\title{
Using Self-Awareness as a Means to Reduce Energy Consumption
}

\author{
Ruth Cloherty ${ }^{1,}$ and Cathrine V. Jansson-Boyd ${ }^{2 *}$ \\ ${ }^{1}$ Department of Psychology, Anglia Ruskin University / East Road, Cambridge, CB1 1PT \\ ${ }^{2}$ Department of Psychology, Anglia Ruskin University / East Road, Cambridge, CB1 1PT \\ E-Mail: cathrine.jansson@anglia.ac.uk
}

* Author to whom correspondence should be addressed; Tel.: +44 (0)845 1962697

Received: 2 September 2014 / Accepted: 31 October 2014 / Published: 3 November 2014

\begin{abstract}
During a period of 6 months, 16 previously homeless male participants from a small town in the UK were encouraged to adopt an intrinsic and environmentally responsible attitude. The aim was specifically to reduce the participants' energy consumption. This was done through self-awareness sessions in parallel with traditional environmental educational sessions. Self-awareness was in this study used as a tool to help guide the participants towards a positive sense of self through the engagement of energy saving behaviors. The self-awareness sessions took place in the form of a series of small group sessions. Focus groups were conducted prior to the self-awareness sessions and individual interviews conducted after they had been completed, in order to measure whether their environmentally held beliefs had changed. Each focus group and interview was structured around their environmentally held beliefs and took less than 1 hour. Thematic analysis was used to analyze the data. The analysis revealed that at the onset the participants lacked interest in energy reduction behaviors. However, after having taken part in the selfawareness sessions it became evident that a shift in attitude had occurred. This investigation was part of a bigger project with the participants in which their social housing underwent retrofitting with air-source heat pumps, to make the houses more energy efficient.
\end{abstract}

Keywords: energy consumption, self-help, self-awareness, homeless 


\section{Introduction}

Within Environmental Psychology it has been long recognized that simply 'teaching' people about conservation behaviors is not enough to actually change the way in which they behave. Changing peoples' behavior can be difficult especially because people are confronted with 'individual barriers' that needs to be overcome [1] prior to any change taking place. In this paper we propose that self-awareness can be utilized as a way to get people to reduce their overall energy consumption, even when people have other pressing life priorities that could be obstacles to altering their behaviors. The study presented here is the final stage of a program whereby we have worked with previously homeless tenants that are currently living in social housing that has been retrofitted with air-source heat pumps (encouraging and facilitating the use of renewable energy sources). Tenants living in the retrofitted blocks have been provided with information on how to effectively use the air source heat pump based systems. They have also been provided with practical information on how to reduce the amount of energy they use.

Previously homeless people can be difficult to engage in behavior change due to often having many other life related issues to deal with. The fact that they may perceive many aspects as obstacles to reducing their energy consumption is one of the key contributions of this paper. We reflect here on the views and perceptions of a group of people that have been less well represented within the energy conservation literature. However, looking at different categories of people when it comes to understanding how we can reduce energy consumption is essential if one truly wish to reduce the energy use within British households.

\subsection{The problem of overconsumption}

People are currently over-consuming the world's resources [2,3]. Such consumption pattern is dysfunctional and correlates with the concept of individualism which stems from the post-industrial narrative in the West [4]. It has been proposed that over-consumption stems from people being disconnected from the natural world and their natural self [5]. The effect of being disconnected from our natural self is not immediately apparent at a surface level. There are many subconscious psychological processes that are invisible such as 'social comparison' [6, 7], which cause people to make social comparisons in order to increase their own sense of self-worth through a sense of superiority $[8,9]$. Superiority in an individualistic society is associated with the ability to consume [10]. Campaigns using social norms to influence consumer related behaviors have seen an increase in undesired behaviors [11]. The desire to conform to social norms is often driven by unconscious and automatic thinking [12]. The norms that many adhere to stem from the unwritten rules for living in an individualistic society $[13,14,15]$ and these rules are promoted and maintained by people with a high 'social dominance orientation' [16]. Such individuals are often willing to exploit the environment in unsustainable ways and more likely to use legitimizing myths in society to support and justify their dominance over nature [17] and maintain an hierarchical power structure [18,19]. Social dominance orientation is also negatively correlated with higher order responses such as empathy, tolerance, communality, and altruism [16]. It is these higher order responses that are required for the survival of humanity [20,21].

\subsection{Benefits of acting altruistically}


Living cooperatively in an altruistic society is a far better survival strategy than living competitively in a hierarchical one [20,22]. People who cooperate achieve better results [23] and formulate better solutions. De Young [24] redefined altruism within the context of the environment. He suggests that being altruistic means striving to do the right thing for ourselves and for others and that it entails being thoughtful about our consumption and making more constructive choices. It is clear that this new definition of altruism belongs to a society that has a new and more sustainable master narrative; one of reciprocity not individualism. Environmental identity is in fact negatively correlated with an individualistic perspective and positively correlated with a collectivist perspective [25,19]. Reciprocal living by its very nature encourages people to regulate their own behavior and therefore act in altruistic ways [26].

\subsection{Alignment of thoughts and behaviors}

Changing people's behavior requires aligning what people actually do with what they think is important and the values they have [27]. Pro-environmental identities can only be established once they are aligned [12]. Hence it seems necessary to become more aware of the beliefs that have been projected onto us in an individualistic society that strives for dominance over others and nature herself. If we are to encourage the adoption of environmentally responsible behaviors (ERBs) in the population, as a whole, we need to recognize where our current beliefs stem from and to update them with more creative and functional beliefs about our-self and the world. It seems important to question and update the information that was uncritically absorbed in early childhood $[28,29]$ and to understand more about the function of emotions in human decision making [30]. Intellectual insight on its own is not enough to change deeply rooted causal beliefs about the self and the world. Patterns of thinking get entrenched over time and any action stemming from the intellect alone is doomed to failure [31]. It is the experiential or subconscious mind that will determine the results of our actions [30]. Experiential memories from our childhood also influence our thinking, feelings and behavior later in life which impacts on our ability to make decisions [32,30,33]. If people have unintegrated emotions from childhood it is these that will surface and be re-lived despite any attempt at rational control [30]. Emotions are therefore a key element in decision making and if we are unable to utilize this source of intelligence our decisions will be negatively affected $[5,34]$.

\subsection{Environmental attachment}

According to eco-psychologists, human beings experience anxiety when disconnected from the natural environment [5]. By using objects relations theory [35,36] our relationship to Mother Earth as our primary caregiver can be used to understand our attachment and resulting separation anxiety [37]. The most common emotions associated with this alienation are anxiety, fear, anger, despair, and shame. It is only by becoming aware of and feeling the emotion that people can release it and free up psychic energy to think more constructively [37]. There is also evidence to suggest there is a direct relationship between feeling and understanding our emotions and our ability to care for others and the environment [38]. Feeling connected with nature gives us a deep sense of reverence towards it; it is this connection that establishes the pro-environmental self-identity and subsequent sustainable behaviors $[39,40]$ No moral or normative influence is required. The altruist's concern for others (including the diversity of life on earth) and future generations is a natural way of being 
and is not necessarily motivated by any personal gain [26]. It is plausible that our natural self is always there - it just needs uncovering by becoming more self-aware.

\subsection{Raising awareness}

Once the individual is aware of his or her early programming and how their own mind operates they are capable of making new choices about how they behave. They will also understand that in order to establish new habitual ERBs they will need to engage the conscious mind, which is more effortful. Having this knowledge will help to motivate the practice necessary to establish new behavior pathways and overwrite the old pathways [28,29]. Even people with pro-environmental attitudes can experience resistance to adopting new pro-environmental behaviors [26]. Guidance and support is required for them to practice within a safe environment (freedom to fail without being judged or criticized) until they reach a point where they feel competent in the behavior [41].

Educating individuals in the role of emotions in decision making is also useful as they can see how being environmentally friendly will be conducive to their own happiness. The proenvironmentalist personally benefits from engaging in ERBs. Learning and becoming competent in new ERB's can lead to pleasurable feelings of satisfaction and a sense of purpose and belonging to both the community and the environment [24]. Environmental identity can be experienced on a number of levels which may include being part of a group with an environmental identity or having a direct relationship with nature as an individual with no social influence. Strengthening environmental self-identity at the individual level and empowering the individual maybe more effective [42]. Empowered individuals who embrace pro-environmental behaviors will themselves become leaders by example [12].

Generally people do fundamentally want to care for the environment; that is probably why we feel good about ourselves when we do engage in ERBs. It is our natural self that is activated and that feels good. People may be influenced initially by external motivations such as saving or gaining money yet these superficial motivations are soon replaced by intrinsic motivations. So the sense of satisfaction that accompanies ERBs can become the main motivation [26]. This may explain why strategies and campaigns to change individual behavior using only financial incentives have had little or no impact [43]. Whilst increasing awareness of the environmental issues is important and the practical knowledge of new behaviors is essential [44]; these do not provide the total solution [45] because they are not addressing the actual cause of the problem. In order to do this we need greater understanding of the self and healthier ways of achieving a positive sense of self-worth. We need strategies that can and do establish ERBs as the norm [46,47,2]

\subsection{Creating a pro-environmental identity}

Gifford [48] reviewed 29 barriers which limit climate change mitigation and adaptation behaviors. Hence it seemed wise to incorporate a range of strategies in our educational campaign to instill new habits [49]. In order to ensure the method used had a lasting effect it seemed pertinent to see if the adoption of a pro-environmental self-identity could be encouraged. To achieve this, participants were educated in how their own brain developed and learned the automatic behaviors that have become a part of their perceived self-identity. Transactional Analysis (TA) was the model of the human psyche used in this study because it is simple for lay people to understand and apply to their own lives [50]. The goal of TA is to bring about 'constructive personality change' [51]. In TA this 
occurs with the emancipation of the part of our mind that makes 'here and now' decisions based on the stored (archaic) data [52]. Christopher [53] describes this process as becoming who we are and being the best that we can be. It is important for our psychological well-being to understand how our perception of the world has been shaped by society and from feeling inferior [54,55,56,57]. If people are not functioning well in life they cannot be expected to engage in learning new behaviors. The rationale for undertaking the following research is to find out if an increased knowledge of the self does enable the process of learning [58] ERBs as well as developing a pro-environmental selfidentity and subsequently reduce energy consumption. The overall aim of this current study was to provide an effective program to facilitate enduring conservation behaviors in this population.

\section{Method}

\subsection{Participants}

Sixteen previously homeless men that lived in supported accommodation took part in this study. They were aged between 25 and 65 years with a mean age of 39 years. Most had been brought up in low status and income groups and their educational background was limited to National Vocational Certificate or GCSE level. None of the participants were in paid employment during the time of the study although some did voluntary work. All participants had previously lived in a hostel. The purpose of the supported housing, which usually ran over six months, was to prepare the tenants for independent living. An opportunistic sampling approach was employed as it worked well for this potentially vulnerable population, some of whom were dealing with addiction and other mental health issues.

\subsection{Materials and Procedure}

Prior to conducting the self-awareness sessions, nine tenants took part in 3 separate focus groups aimed to measure participants' thoughts and feelings about energy consumption and environmentally friendly behaviors. There were two groups of two participants and one group of five participants. During the focus group they were prompted by a researcher to discuss topics such as what the benefits would be if the participants became more environmentally aware and what the personal benefits may be if they reduced their energy consumption. Most questions were broad in nature to ensure that the participants could describe how they felt about environmental issues, energy consumption, and how they perceived their own responsibility in adopting conservation behaviors. In total they were asked 11 questions and the length of the focus groups ranged from 40 to 57 minutes. All three focus groups were recorded.

The 3 self-awareness sessions were delivered in a group setting. Self-awareness material was delivered by showing the participants a Microsoft PowerPoint presentation on a laptop. Each presentation was structured so that it introduced the participants into the concept of TA as well as how it can be used as a tool to change their energy consumption behaviors. At the end of each presentation participants had the opportunity to ask questions and a small discussion around the topics presented was facilitated by the researcher. 
The first self-awareness session 'exploring how people can change' was delivered seven weeks after the focus group interviews. This session served as a simple introduction to how the human brain develops and processes information. In this session it was explained how the brain formulates the sense of a self-identity in order to function in the world. It also explored how the power of care-givers and early-life teachers can influence the sense of self. Furthermore, they were also introduced to the concept that people can consciously alter behavior that was previously unconscious behavior in order to make it more functional.

In the second session, which was delivered four weeks after the first self-awareness session, participants were introduced to the concept of altruism as well as an outline of how the human mind works. It focused on the key aspects of the TA model and how it can be applied to deal with the links between the self and conservation behaviors. One of the fundamental concepts of TA is that young developing human beings have a tendency (just from the nature of our upbringing and how the human mind works) to formulate a self-belief that it is not okay [50]. The model goes on to explain that in order to feel okay about ourselves (feeling not okay is uncomfortable and also not correct) we make others not okay in our mind. This gives us a superficial sense of superiority and we feel temporarily okay. This helps explain why we engage in social comparisons. The purpose of this session was to enable the participants to better understand what has influenced their perception and therefore their experience of the world.

The third and final self-awareness session was delivered one week after the second session. It focused on the positive link between altruism and reciprocal living, stating that altruistic behavior can lead to positive experiences such as satisfaction from learning new environmentally related behaviors. In particular the session looked at problem solving, understanding and substituting emotions, and the link between joy and engaging in ERBs.

After the 3 self-awareness sessions had been conducted ten of the participants took part in a semistructured interview. Five of these were the same as those who took part in the pre self-awareness session focus groups. The purpose of the interview was to determine if the self-awareness sessions had affected the way in which they view environmentally related behaviors and in particular energy consumption. Consequently they were asked what factors they thought influenced their energy consumption behaviors and whether they believed it was important to be environmentally friendly. They were also asked if they thought that their early life experiences had molded their view of energy consumption. In total they were asked 10 questions and the interview length varied from 12 to 37 minutes and all interviews were recorded.

\subsection{Data analysis}

The recorded data for the focus groups and the individual interviews was transcribed and then analyzed using thematic analysis. We followed Braun and Clark's [59] six step thematic analysis guidelines. The starting point is to become familiar with the data by going through the data several times. Steps two to five occur in a cyclical process and include the coding of interesting features, searching for themes, the inter-correlation of themes and coded extracts and defining and naming themes. The sixth is the writing of the report. In this study the analysis was guided by some previously identified areas of interest as well as by openness to previously unanticipated themes and 
sub-themes. To ensure consensus in terms of data interpretation two researchers are engage in the process, throughout.

\section{Results and Discussion}

The participating tenants were interviewed in focus groups 3 weeks prior to the self-awareness sessions and again individually just over 2 weeks after the self-awareness sessions. The recorded data was transcribed and analyzed using thematic analysis and what follows are the key themes identified from the focus groups pre self-awareness sessions and interviews post self-awareness sessions. The themes clearly show how the participant's attitude to energy conservation changed after the self-awareness sessions. Please note that pseudo names are used to protect the identity of the participants.

\subsection{Focus group data (pre self-awareness sessions)}

One main theme, Willingness to Engage in ERB's and three sub-themes emerged from the qualitative analysis of the pre-self-awareness sessions focus group interview data.

\section{(1) Willingness to Engage in ERBs}

The theme 'willingness to engage in ERBs' is like a snapshot of the participant's general attitude towards energy conservation. It includes a number of fairly broad sub-themes that together cover quite a large area. Throughout there was some evidence that the participants attempted to engage in some energy saving behaviors that they had previously been informed about. In the three subthemes included here participants express views such as that 'there is no point in engaging in ERB's' and that 'individual ERBs do not make a difference' a deep seated negative attitude towards energy conservation behaviors becomes evident. After all it takes effort to change behavior and to engage in learning new behaviors.

\section{(1.1) Benefits of ERB's}

Although the tenants were aware that they would save money by using less electricity some of them could not see an immediate benefit to themselves as they were not paying for the electricity directly;

Bob: "There is nothing personal for us now it would be in the future that would be."

Some of the tenants could see that there were long-term benefits for future generations;

Steve: “Not personal benefits, no (inaudible) it's more our children or our children's children, you know."

They could also see that there would be some environmental benefits of using less electricity.

Bob: "Would it be cleaner air?" 
John: Well they'd use less wouldn't they? Less fossil fuels being used. Well less global warming.

\section{(1.2) No point in engaging in ERBs}

Overall the general consensus was that there was no point in engaging in ERB's as any actions that they took as individuals would be inconsequential. Steve thought that in comparison to the petroleum industry - the individual's impact on climate change was insignificant.

Steve: "Yes, turning the telly, not turning the telly on standby, you know, an LED light is, is inconsequential compared to the pollutants that Esso pump out into the ozone layer every minute of every day, you know."

There was also evidence of a negative social influence from others who seemed to waste energy. Bob voiced his concern that engaging in ERB's seemed pointless when other people did not seem to care if they were wasting electricity.

Bob: "People leave electrics on stand-by twenty-four-seven."

Craig commented on his flat-mates behavior and it is clear that Craig feels unable to encourage his flat-mate to use less energy when using the kettle to make a hot drink for just him-self.

Craig: "Dave will fill it right to the top for one cup (laughs). But how can I stop him from doing that? Even if I mark it he'd probably still."

\section{(1.3) Individual ERBs do not make a difference}

There was a general consensus among the group of tenants that it was more important for industry to reduce its consumption of electricity and subsequent pollution. Steve was quite angry about the way individuals are being held accountable whilst in his view industry was the main polluter and contributor to climate change.

Steve: "Well I think personally, I think industry should hold more sway than the single person leaving his telly on standby, turning his tap off in between brushing his teeth and spitting out the toothpaste sort of thing, you know? I think that, that big Industries, big conglomerates should be held more responsible than, as a people, you know, as a person."

\subsection{Individual interview data (post self-awareness sessions)}

Two main themes and two sub-themes for each of the main themes, emerged from the individual interview data. 


\section{(1) Changing human behavior}

This theme encompasses the specific ERBs that the participants are doing as well as reflects the shift in their sense of individual responsibility towards the environment. It is clear from what they are saying that these new behaviors have meaning for them which is both satisfying and enjoyable. The two sub-themes are; 'engaging in ERBs' and 'can the individual make a difference'.

\section{(1.1) Engaging in ERBs}

It is clear to see that the tenants have a positive attitude towards engaging in ERBs and are actively engaging in several energy saving behaviors. Nine out of the ten participants reported that they had changed their energy-use behaviors and were only using the amount of electricity that they needed. John and Carl enthusiastically explain some of the new energy saving behaviors that they are engaging in.

John: "Well, as what you've taught me and the kettle and, and I don't leave things on stand-by no more. I don't charge my phone at night time no more, I actually charge it while I am sitting there ... it saves quite a lot and obviously when I am actually paying my own bills it will save me a few bob as well."

Carl: "Yeah without a doubt - I used to have it - top it up (4:00) a lot of the time but now I just use, use what I need."

Some of the tenants express having a more positive sense of self and felt inspired to educate others. Stewart expresses a very positive sense of self and others and John also appears to have internalized the new behaviors and is excited about passing on the knowledge.

Stewart: “..., you feel better in yourself, you feel better for other people, in yourself you feel positive and you feel good about it, you feel better."

John: "Well I told you, I must have spoken to perhaps ten people about this, what you've told and then, them ten tell ten."

\section{(1.2) Can the individual make a difference?}

In the post-session interviews the participants were far more accepting of the responsibility that they have as an individual regardless of what others are doing. Simon and Carl could see that each individual contribution does make a difference. 
Simon: "Yes I think if every person does their own little bit then it will improve the environment or help."

Carl: "Oh right, well, um, it's like a movement moving forward. If, if everybody starts, like, to make a change and you continue to make a change yourself, you know that in the long run it's going to benefit, going to benefit all of us. And hopefully it will have that knock on effect which obviously we want it to be doing; in having everyone, everyone would be re-wired to be doing like the things that should be done."

The majority of the tenants also felt positive about their individual contribution, despite it being relatively small, because they felt they were doing their best. Carl was quite optimistic about the momentum that could develop by individuals actively engaging in ERBs. Nigel could see that it was worthwhile engaging in ERBs despite having a small effect.

Carl: "Oh right, well, um, it's like a movement moving forward. If, if everybody starts, like, to make a change and you continue to make a change yourself, you know that in the long run it's going to benefit, going to benefit all of us. And hopefully it will have that knock on effect which obviously we want it to be doing; in having everyone, everyone would be re-wired to be doing like the things that should be done."

Nigel: "...which is cut down on me, the amount of electric I use and the heating but in the meantime I am only a little small cog - so I'd say only a little bit but I am doing what I can."

We can be influenced by the behavior of others, especially those we deem as similar to ourselves. This can lead to the adoption of either negative or positive behaviors. Bob voices this dilemma that can be experienced by the potential eco-warrior when others are not environmentally aware.

Bob: I do feel good yeah. I sometimes think "why do I bother? When I see people with lights on all night, you know."

Over one half of the tenants could see that they could influence others by actively engaging in ERBs themselves. Simon is quite clear about the fact that if they do not embrace the ERBs then no one else will and Ian could see that that his behavior could 
have a knock on effect onto others.

Simon: "Well yes I think if every person does their own little bit then it will improve the environment or help, you know, if I say no, if everyone says no then they're not going to."

Ian: "I am still doing my bit and I will always do my bit...it's a domino effect."

\section{(2) Reducing consumption}

The emerging emphasis in this theme reflects the steps these men have taken on their journey to becoming bio-centric individuals. In the first sub-theme 'willingness to learn and apply new energy-saving behaviors' it is evident how they have adopted the ERBs and used the self-awareness material to make new decisions about how they want to behave. In the second sub-theme 'why we need to adopt ERBs' it is clear that they have embraced a broader sense of self and are including the planet and all its diversity in that self.

\section{(2.1) A willingness to learn and apply new energy-saving behaviors}

The majority of tenants reported having reduced their electricity consumption and a willingness to learn and apply the new energy-saving behaviors. Bob and Ian attribute this shift in attitude to the project.

Bob: "Well frankly before doing this project I used to have my things on stand-by twentyfour seven, you know, all day and had lights on and now I turn them off and I actually consider what I am using."

Ian: "Well attending the course has helped because it has given me a better understanding of what I can do to lower my energy I use."

Some of the tenants reported that becoming more self-aware had been helpful in helping them understand their behavior and to help them choose new behaviors. Ian and Bob both made inferences to early programming and becoming more aware of the unconscious processes that occur in human thinking.

Ian: "I guess from when I was a child to as I am now, you know, I've seen a lot of changes - in myself....Yeah I think so and I am understanding why I made those decisions." 
did it, you know, so I am going to teach my children if I have any to turn things off (inaudible) more self-aware of what we use and."

\section{(2.2) Why we need to adopt ERBs}

There was a greater sense of altruism (according to De Young's definition) in the majority of the tenants with seven out of ten making specific comments that allude to this. Paul saw humans engaging in ERBs as essential for other life forms and the diversity of the planet. Carl was concerned with the planet and for future generations.

Paul: "Not just animals, diversity, rain forests stuff like that."

Carl: "Okay, yeah I do believe that it is very important to be environmentally friendly, um, as in the long run, it will have, um, um, the I'm sure it will have a knock on effect and in years to come we can make our environment either greener or we can reduce on pollution, um, yeah I think it's important for our next generation."

There was also a general consensus that by reducing energy consumption global warming could be reduced.

Ian: "Well there'd be probably less global warming"

John: "The ozone layer may last longer, I don't know"

\section{Conclusions}

The overall aim of this current study was to provide an effective programme to facilitate enduring conservation behaviors in this population by increasing their self-awareness. This study has shown that increased self-awareness did positively affect the ability of the participants to learn and adopt [58] new ERBs and to form a pro-environmental self-identity. Understanding about their own self and how that self was formulated appears to have freed up some cognitive capacity to learn new behaviors. By reducing the level of stress through self-awareness it may have reduced the amount of inner conflict between personal values [12]. Importantly it does seem that the natural self [5] is naturally empathetic and concerned for others and the environment [26] which is at odds with the current master narrative of individualism [18] and our early programming [28]. Some of the participants also felt motivated to educate others in ERBs and also felt they were leading by example [12]. This would suggest that they have adopted a pro-environmental self and that they are also experiencing the intrinsic satisfaction that is linked to altruism [24]. 
The authors suggest that self-awareness education may be the key to extinguishing the impasse that has been experienced in the field of sustainability and environmental psychology. When delivered alongside a specific education in ERBs is appears to be effective. This population is also quite extreme as they have all experienced many personal difficulties that they were previously not able to cope with. The authors feel it is imperative to explore this avenue further. By producing people who are motivated to educate others the desired result of an environmentally friendly consciousness amongst the collective will be achieved.

Because this investigation was part of a bigger project with the participants in which their social housing underwent retrofitting with air-source heat pumps, to make the houses more energy efficient, participants' energy usage was monitored using smart meters. Such monitoring supported the results from the thematic analysis in that it showed a decrease in energy use during the 6 months period the participants attended self-awareness sessions.

\section{Acknowledgments}

This study was funded by the European Regional Development Fund (ERDF). We would like to thank them as well as all the others that have directly or indirectly been involved in this project.

\section{Conflict of Interest}

The authors declare no conflict of interest.

\section{References}

1. Robison, R. A.V.; Jansson-Boyd, C.V. Perspectives on Sustainability: Exploring the Views of Tenants in Supported Social Housing. Sustainability 2013, 5, 5249-5271.

2. Jansson-Boyd, C. Consumption matters. Palgrave Macmillan Basingstoke, Hampshire, 2011.

3. Amin, A.; Thrift, N. What's left? Just the future. Antipode 2005, 37, 220-238.

4. Porritt, J. (2004). Foreward. In M. Gold. The global benefits of eating less meat. A Report for compassion in World Farming Trust. Retrieved January 10, 2008 from http://www.ciwf.org/publications/reports/The_Global_Benefits_of_Eating_Less_Meat.pdf

5. DuNann Winter, D. Some big ideas for some big problems. American Psychologist 2000, 55, 516-522.

6. Festinger, L. A theory of social comparison processes. Human Relations 1954, 7, 117-120.

7. Wills, T. A. Downward comparison principles in social psychology. Psychological Bulletin 1981, 90, 245-271.

8. Fein, S., \& Spencer, S. Prejudice as self-image maintenance: Affirming the self through derogating others. In C. Stangor (Ed.). (2003) Stereotypes and prejudice. Psychology Press: Hove, East Sussex, 1997.

9. Billig, M. Prejudice, categorization and particularization: From a perceptual to a rhetorical approach. European Journal of Social Psychology 1985, 15, 79-103. 
10. Kanner, A. D.; Gomes, M. E. The all-consuming self. In T. Rosak. G. A. Gomes,; Kanner (Eds). Ecopsychology: Restoring the earth, healing the mind (pp. 77-91). Sierra Club: San Fransisco, USA, 1995.

11. Schultz, W. P.; Nolan, J. M.; Cialdini, R.B.; Goldstein, N. J.; Griskevicius, V. The constructive, destructive, and reconstructive power of social norms. Psychological Science, 2007, 18 (5), 429 $-434$.

12. Linda Steg' L; Bolderdijk, J. M.; Keizer. K.; Perlaviciute, G. An integrated framework for encouraging pro-environmental behaviour: The role of values, situational factors and goals. Journal of Environmental Psychology 2014, 38, 104-115.

13. Schwartz, S. H.; Howard, J. A. Helping and cooperation: A self-based motivational model. In V. J. Derlage \& J. Gizelack (Eds.), Cooperation and helping behaviour: Theories and research. Academic Press: New York, 1982.

14. Berkowitz, L. Social norms, feelings, and other factors affecting helping and altruism. In L. Berkowitz (Ed.), Advances in Experimental Social Psychology, Vol. 6 (pp. 63-108). Academic Press: San Diego, CA, 1972.

15. Miller, D. T.; Prentice, D. A. The construction of social norms and standards. In E. T. Higgins \& A. W. Kruglanski (Eds.), Social psychology: Handbook of basic principles (pp. 799- 829). Guilford Press: New York, 1996.

16. Pratto, F.; Sidanius, J.; Stallworth, L. H.; Malle, B. F. Social dominance orientation: A personality variable predicting social \& political attitudes. Journal of Personality and Social Psychology 1994, 67, 741-763.

17. Milfont, T. L.; Duckitt, J. The structure of environmental attitudes: A first- and second-order confirmatory analysis. Journal of Environmental Psychology 2004, 24, 289-303.

18. Milfont, T. L.; Richter, I., Sibley, C. G.; Wilson, M. S.; Fischer, R. Environmental consequences of the desire to dominate and be superior. Personality and Social Psychology Bulletin 2013, 39(9) 1127-1138.

19. Milfont, T. L.; Sibley, C. G. The hierarchy enforcement hypothesis of environmental exploitation: A social dominance perspective. Journal of Experimental Social Psychology 2014, 55, 188-193.

20. Buss, D. M. Evolutionary Psychology: A New Science of the Mind ( $4^{\text {th }}$ ed.). Allyn \& Bacon, an imprint of Pearson London, 2012.

21. Sapolsky, R. M. Why zebras don't get ulcers ( $3^{\text {rd }}$ Ed.). St. Martin's Griffin: New York, 2004.

22. Axelrod, R.; Hamilton, W. D. The evolution of cooperation. Science 1981, 211(4489), 1390 1396.

23. Carnevale, P. J.; Probst, T. M. Social values and social conflict in creative problem solving and categorization. Journal of Personality and Social Psychology 1998, 74(5), 1300-1309.

24. De Young, R. Expanding and evaluating motives for environmentally responsible behaviour. Journal of Social Issues 2000, 56(3), 509-526.

25. Clayton, S.; Opotow, S. Justice and identity: Changing perspectives on what is fair. Personality and Social Psychology Review 2003, 7(4), 298-310.

26. De Young, R. Some psychological aspects of reduced consumption behaviour. The role of intrinsic satisfaction and competence motivation. Environment and Behaviour 1996, 28, 358409.

27. Cialdini, R. B. Crafting normative messages to protect the environment. Current Directions in Psychological Science 2003, 12(4), 105-109.

28. Hood, B. The self-illusion. Constable: London, 2012.

29. Kahneman, D. Thinking, fast and slow. Penguin Books: London, 2011.

30. Epstein, S., \& Meier, P. Constructive thinking: A broad coping variable with specific components. Journal of Personality and Social Psychology 1989, 57(2), 332-350.

31. Fromm, E. Man for Himself. Routledge: Abingdon, Oxon, 2003. p167

32. Goleman, D. Emotional Intelligence. Bloomsbury Publishing: London, 1996.

33. Berne, E. What Do You Say After You Say Hello? Corgi Books: London, 1975. 
34. Franklin, S. S. The Psychology of Happiness: A Good Human Life. Cambridge University Press: New York, 2010. p23

35. Buckley, P. Essential Papers on Object Relations. New York University Press: New York, 1986.

36. Greenberg, J. R.; Mitchell, S. A. Object Relations in Psychoanalytic Theory. Harvard University Press: Cambridge MA, 1983.

37. Bowlby, J. Attachment and loss. Pimlico: London, 1969.

38. Perkins, H.E. Measuring love and care for nature. Journal of Environmental Psychology 2010, 30, 455-463.

39. Shultz, P. W. Empathizing with nature: The effects of perspective taking on concern for environmental issues. Journal of Social Issues 2000, 56(3), 391-406.

40. Mayer, F. S.; Frantz, C. M. The connectedness to nature scale: A measure of individuals' feeling in community with nature. Journal of Environmental Psychology 2004, 24(4), 503-515.

41. White, R. W. Motivation reconsidered: The concept of competence. Psychological Review, 1959, 66, 297-233.

42. Cialdini, R. B. The role of social (versus financial) factors in environmental action. Keynote lecture presented at the $28^{\text {th }}$ International Congress of Applied Psychology, Paris, France. 2014, July.

43. Lorenzoni, I.; Nicholson-Cole, S.; Whitmarsh, L. Barriers perceived to engaging with climate change among the UK public and their policy implications. Global Environmental Change 2007, 17, 445-459.

44. Staats, H.; Harland, P.; Wilke, H. A. M. Effective durable change: A team approach to improve environmental behaviour in the household. Environment and Behaviour 2004, 36(3), 341-367.

45. Staats, H.; Harland, P.; Wilke, H. A. M. Effective durable change: A team approach to improve environmental behaviour in the household. Environment and Behaviour 2004, 36(3), 341-367.

46. Stern, P. C. Psychology and the science of human-environment interactions. American Psychologist 2000, 55, 523-530.

47. Abrahamse, W.; Steg, L.; Vlek, C.; Rothengatter, T. A review of intervention studies aimed at household energy conservation. Journal of Environmental Psychology 2005, 25, 273-291.

48. Gifford, R. The dragons of inaction: psychological barriers that limit climate change mitigation and adaptation. American Psychologist 2011, 66, 290-302.

49. Steg, L.; Vlek, C. Encouraging pro-environmental behaviour: An integrative review and research agenda. Journal of Environmental Psychology 2009, 29, 309-317.

50. Harris, T. A. I'm Okay, You're Okay. CPI Cox \& Wyman: Reading, 1995.

51. Rogers, C. R. The necessary and sufficient conditions of therapeutic personality change. The Journal of Consulting Psychology 1957, 21 (2) 95 -103.

52. Berne, E. Transactional analysis: A new and effective method of group therapy. American Journal of Psychology 1958, 12, 735-743.

53. Christopher, J. C. Counseling's inescapable moral visions. Journal of Counseling and Development 1996, 75(1), 17-25.

54. Christopher, J. C. Situating psychological well-being: Exploring the cultural roots of its theory and research. Journal of Counseling \& Development_1999, 77(2), 141-152.

55. Christopher, J. C., Richardson, F. C., \& Christopher, S. E. Philosophical hermeneutics: A metatheory to transcend dualism and individualism in western psychology. From an earlier published symposium: In K. D. Smith (Chair), Metatheories in the Natural Sciences and in Cross-Cultural Psychology. Symposium conducted at the International Congress of the International Association for Cross-Cultural Psychologists, Warsaw, Poland. 2000.

56. Gilbert, P. Compassion Focused Therapy. Routledge: London, 2010.

57. Ryle, A., \& Kerr, I. B. Introducing Cognitive Analytic Therapy; Principles and Practice. John Wiley \& Sons Limited: Chichester, West Sussex, 2002.

58. Jones, D. Mindfulness in schools. The Psychologist 2011, 24(10), 736-739. 
59. Braun, V.; Clarke, V. Using thematic analysis in psychology. Qualitative Research in Psychology 2006, 3, 77-101. 